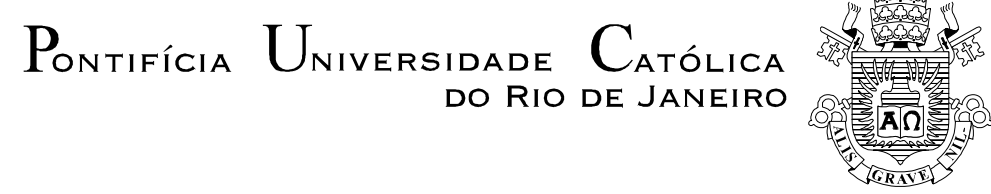

Andréa Monteiro Dalton

Os Direitos Humanos à luz do Código de Ética do Serviço Social e do Estatuto da Criança e do Adolescente:

Afinal, o que estamos defendendo?

Dissertação de Mestrado

Dissertação apresentada como requisito parcial para obtenção do grau de Mestre pelo Programa de Pósgraduação em Serviço Social do Departamento de Serviço Social da PUC-Rio.

Orientadora: Prof ${ }^{a}$ Irene Rizzini 
Andréa Monteiro Dalton

\title{
Os Direitos Humanos à luz do Código de Ética do Serviço Social e do Estatuto da Criança e do Adolescente: \\ Afinal, o que estamos defendendo?
}

Dissertação apresentada como requisito parcial para obtenção do grau de Mestre pelo Programa de Pósgraduação em Serviço Social do Departamento de Serviço Social do Centro de Ciências Sociais da PUC-Rio. Aprovada pela Comissão Examinadora abaixo assinada.

\author{
Profa Irene Rizzini \\ Orientadora \\ Departamento de Serviço Social - PUC-Rio \\ Prof ${ }^{\mathrm{a}}$ Maristela Dalmoro \\ UFRJ \\ Prof ${ }^{\text {a }}$ Mônica Alencar \\ UERJ \\ Prof. Nizar Messari \\ Vice-Decano de Pós-Graduação do \\ Centro de Ciências Sociais - PUCC-Rio
}

Rio de Janeiro, 13 de maio de 2008 
Todos os direitos reservados. É proibida a reprodução total ou parcial do trabalho sem autorização da universidade, da autora e do orientador.

\section{Andréa Monteiro Dalton}

Graduou-se em Serviço Social na Faculdade Salesiana de Vitória em 2005. Participou de diversos congressos na área de Serviço Social. Ministrou Mini-Curso sobre A Política de Atendimento à Criança e ao Adolescente no Brasil na Faculdade Salesiana de Vitória e na Faculdade Metodista do Espírito Santo. Atualmente trabalha como Professora no Curso de Serviço Social na Universidade Federal do Espírito Santo - UFES e na Faculdade Salesiana de Vitória ES.

Ficha Catalográfica

Dalton, Andréa Monteiro

Os direitos humanos à luz do Código de Ética do Serviço Social e do Estatuto da Criança e do Adolescente / Andréa Monteiro Dalton; orientadora: Irene Rizzini. - 2008.

$114 \mathrm{f.} ; 30 \mathrm{~cm}$

Dissertação (Mestrado em Serviço Social)-Pontifícia Universidade Católica do Rio de Janeiro, Rio de Janeiro, 2008.

Inclui bibliografia

1. Serviço social - Teses. 2. Direitos humanos. 3. Código de Ética do Serviço Social. 4. Estatuto da Criança e do Adolescente. I. Rizzini, Irene. II. Pontifícia Universidade Católica do Rio de Janeiro. Departamento de Serviço Social. III. Título. 
A todos aqueles que, ao longo da história, derramaram o próprio sangue em nome do sonho de dias melhores. 


\section{Agradecimentos}

A Deus, que sempre provê e sempre proverá;

Ao CNPq e a PUC-Rio, pelo fundamental apoio financeiro;

À minha orientadora, Irene Rizzini, pelos sábios ensinamentos, pela compreensão e pela oportunidade de conhecer e admirar a sua larga experiência;

As profissionais de serviço social, sujeitos da pesquisa, pela participação e fundamental contribuição nas reflexões.

À querida Maristela Dalmoro, que me alojou no mais qualificado albergue carioca, pela atenção e carinho ao longo dessa jornada. A você, minha eterna gratidão;

A Mônica Alencar, pela disponibilidade de participar das minhas bancas e contribuir com a construção desse trabalho... Obrigada pelas suas simpatia e atenção;

À minha família que sempre me apoiou com orações, recursos financeiros, compreensão, força e amor. Ao meu super marido, Felipe, que foi um verdadeiro parceiro nesta caminhada! Aos meus amados pais, Adriano e Gilcéia, às minhas irmãs, Adriana e Gilciane, as minhas sobrinhas e sobrinho que são os meus eternos amores, Driely, Catherine, Allana e João Diego, à minha querida avó, Nair. Aos primos, cunhados e cunhadas pela escuta;

A minha parceira de viagens e aventuras, sem a qual talvez não tivesse chegado até aqui. A você Alaísa, o meu muito obrigado!

A querida Fabricia e ao Teia pela oportunidade de lapidar o meu gosto pela dimensão investigativa o qual me motivou trilhar esse caminho.

A Silvia, Eliana, Cenira e Jaqueline pela força, acolhida nos momentos de aflição. Muito obrigada;

Aos colegas de turma, professores e funcionários do departamento de serviço social, pelo carinho e convivência. 


\section{Resumo}

Dalton, Andréa Monteiro; Rizzini, Irene. Os Direitos Humanos à luz do Código de Ética do Serviço Social e do Estatuto da Criança e do Adolescente: Afinal, o que estamos defendendo? Rio de Janeiro, 2008, 114p. Dissertação de Mestrado - Departamento de Serviço Social, Pontifícia Universidade Católica do Rio de Janeiro.

O objetivo central dessa dissertação é analisar as concepções dos assistentes sociais acerca dos direitos humanos a partir dos princípios que os fundamentam no Código de Ética do Serviço Social e no Estatuto da Criança e do Adolescente. No intuito de alcançar este objetivo, realizei uma ampla pesquisa bibliográfica acerca das categorias de estudo e analisei alguns documentos normativos da profissão e dos direitos da criança e do adolescente. Utilizei ainda, como método de abordagem, a pesquisa qualitativa e a técnica de entrevista semi-estruturada, orientada por um roteiro contendo perguntas abertas, direcionadas aos assistentes sociais, que atuam em instituições na área da criança e do adolescente no Espírito Santo. O referencial teórico adotado foi o método crítico-dialético, o que possibilitou analisar os direitos humanos enquanto um processo contraditório e de luta entre as classes que compõem a sociedade. Através do embate entre as classes, em vários momentos históricos, a classe trabalhadora avançou no sentido de inserir nas leis os direitos coletivos; porém, o controle do Estado está nas mãos dos que precisam expandir o capital. Assim, os direitos não são materializados em sua plenitude. A partir deste estudo, indico a necessidade de os profissionais terem clareza crítica dos fundamentos e funcionalidades da realidade posta, permitindo, assim, observar de forma mais nítida a não- efetivação dos direitos das crianças e dos adolescentes, e ainda avançar, juntamente com a luta geral dos trabalhadores, na materialização do Código de Ética em prol de uma sociedade mais justa.

\section{Palavras-chave}

Direitos Humanos, Código de Ética do Serviço Social e Estatuto da Criança e do Adolescente. 


\section{Abstract}

Dalton, Andréa Monteiro; Rizzini, Irene (Advisor). Human Rights in the light of the Social Work Code of Ethics and the Brazilian Statute for Children and Adolescents: What are we defending, anyway? Rio de Janeiro, 2008. 114p. Msc Dissertation - Departamento de Serviço Social, Pontifícia Universidade Católica do Rio de Janeiro.

This study aims mainly at analyzing the conceptions of social workers about human rights based on the principles on which they are founded in the Social Work Code of Ethics and the Brazilian Statute for Children and Adolescents. Intending to achieve this objective, I carried out and extensive bibliographical research about the categories of study and analyzed some normative documents about the profession and about the children and adolescents' rights. As approach method, I also used qualitative research and semi-structured interview technique, which was guided by a script containing open ended questions, addressed to social professionals working in children and adolescents institutions in Espírito Santo. The theoretical basis adopted was the critical-dialectic method, which allowed analyzing human rights and as a contradict and social class struggle process. Through class struggle in several historical moments, the working class advanced towards inserting collective rights into the law. However, the control of the State is in the hands of those who need to expand capital therefore, rights are not fully materialized. From this study, I point out that these professional should be clearly critical about the fundaments and functionality of the posed reality, allowing thus, observing more clearly the non exercise of children and adolescents' rights, and also advance, together with the working class general struggle, towards the materialization of the Code of Ethics, for a fairer society.

\section{Keywords}

Human Rights, Social Work Code of Ethics and the Brazilian Statute for Children and Adolescents 


\section{Sumário}

$\begin{array}{ll}\text { 1. Introdução } & 11\end{array}$

2. Os Direitos Humanos e sua construção contraditória 20

3. O serviço social no Brasil nos anos 1990: consolidação do 28 amadurecimento teórico metodológico crítico

3.1. Antecedentes Históricos 28

3.2. Os princípios fundamentais no Código de Ética: construção 36 coletiva e hegemônica

3.2.1. Os onze princípios do Código de Ética 37

4. Os direitos da criança e do adolescente no Brasil 45

4.1. Antecedentes históricos 45

4.2. Os direitos fundamentais das crianças e dos adolescentes 53 no Estatuto da Criança e do Adolescente

5. As concepções dos assistentes sociais acerca dos direitos

63 humanos à luz do Código de Ética do Serviço Social e do Estatuto da Criança e do Adolescente: novas possibilidades e velhos limites

5.1. Concepções dos direitos humanos 68

5.2. Concepções acerca dos direitos humanos articulados aos 71 direitos da criança e do adolescente

5.3. Limites à efetivação dos direitos da criança e do adolescente 75

5.4. Limites e possibilidades profissionais 80

6. Considerações finais 86

$\begin{array}{ll}\text { 7. } & \text { Referências bibliográficas }\end{array}$

8. Anexos 94

8.1. Anexo 1. Código de Ética Profissional dos Assistentes 95 Sociais - Princípios Fundamentais

8.2. Anexo 2.Estatuto da Criança e do Adolescente - Livro 1999

8.3. Anexo 3. Roteiro de entrevista 114 


\section{LISTA DE SIGLAS}

ABEPSS - Associação Brasileira Ensino e Pesquisa em Serviço Social

CFESS - Conselho Federal de Serviço Social

CONANDA -Conselho Nacional dos Direitos da Criança e do Adolescente

CRESS - Conselho Regional de Serviço Social

ENESSO - Executiva Nacional de Estudantes de Serviço Social

ONU - Organização das Nações Unidas

SINASE - Sistema Nacional de Medidas Sócio-Educativas. 
“..Não importa onde você parou...

Em que momento da vida você cansou...

O que importa é que sempre é possível e necessário recomeçar.

Recomeçar é dar uma nova chance a si mesmo...

É renovar as esperanças na vida e, o mais importante...acreditar em você de

novo.

Sofreu muito neste período?

Foi aprendizado...

Chorou muito?

Foi limpeza de alma...

Ficou com raiva das pessoas?

Foi para perdoá-las um dia...

Sentiu-se só por diversas vezes?

É porque fechaste a porta até para os anjos...

Acreditou em tudo que estava perdido?

Era o inicio de tua melhora...

Onde você quer chegar?

Ir alto?

Sonhe alto...

Queira o melhor do melhor...

Se pensamos pequeno..Coisas pequenas teremos...

Mas se desejarmos fortemente o melhor e principalmente lutarmos pelo melhor...

O melhor vai se instalar em nossa vida.

Por que sou do tamanho daquilo que vejo.

E não do tamanho da minha altura."

Carlos Drummond de Andrade

Toda vontade de romper e de inaugurar

produz medo. Medo diante do aberto e inesperado; do acontecimento; das histórias cujo desenlace não conhecemos (...), de tudo que sacuda nossa rotina de pensar, de sentir, de amar e de imaginar" Francisco Ortega 